\title{
FATIGUE DAMAGE EVALUATION IN MULTIFASTENED CFRP JOINTS
}

A. De Iorio*, L. Lecce** and S. Mignosi***

${ }^{*}$ Istituto Costruzione Macchine, Fac. Ingegneria, Univ. di Napoli, Italy

${ }^{* *}$ Istituto Progetto Velivoli, Facoltà Ingegneria, Univ. di Napoli,

\section{ABSTRACT}

Fatigue damage in CFRP douple lap joints under constant amplitude load has been evaluated using a computer controlled servohydraulic test machine. The evaluation criterion - To define a damage parameter; To measure this paevalution (taking into account that it is contect to two coexisting phenomena: the degradation of the mechanical connection and the structural degradation the degradation of the mechanical connection and the structural degradation
of the material); - To follow the variations of the measured parameter due to the fatigue.

\section{KEYWORDS}

Mechanical connection; CFRP joints; fatigue damage propagation; graphite epoxy laminate; hysteresis loop control.

\section{INTRODUCTION}

Fatigue damage evaluation, necessary to predict service behaviour of whatever structural component under variable amplitude loads, is still an unsolved engineering problem, due to the difficulties of understanding the complex alteration and If this problem is realy true for a metallic, simple shape component, like a simply notched or unnotched specimen, it is much more serious for bolted joints, with complete load transfer, and non metallic materials, i.e. graphiteepoxy composites, as evaluated here.

In fact, fatigue degradation in mechanical joints, made by composite laminates, starts with a slippage between the faying surfaces, with subsequent alte ration in these surfaces and in bolt clamping forces; later, local high strains arise in the material, bearing increase in the holes where the clearance is lower, until the material delaminates and fibres break. The superimposition of the two phenomena: the degradation of the mechanical connection of the joint and the structural alteration of the laminate, makes it difficult to quan tify the damage due to each single phenomenon, despite the fact that the former 
prevails over the latter in the beginning of the test, and vice versa at the end. Moreover, the casual distribution of the clearances between holes and bolts justifies the statistical approach, that makes it necessary to test a high number of specimen. Any way, the knowledge of the values of the single clearance can help to interpret the meaning of the variability from specimen to specimen of the fatigue behaviour, under the same loads, test frequency and cycle number.

The technical literature on this subject is not very large (Agarwal, 1979; Castellano and co-workers , 1980; Hart Smith, 1980; Schutz, 1978), despite the extensive investigation over these years (Amijima, 1982; Chi-Hung Shen and Springer, 1977; Garbo and Ogonowski, 1979; Reifsnider, 1976; Whitney and ki 1977) of the graphite-epoxy fatigue behaviour (in terms of: material fatigue strength, specimen geometry, environmental and test conditions).

In the meantime the technical interest about the joints of carbon fiber rinforced plastics (CFRP) is increased considerably, expecially in the aeronautic field, due to the possibility to substitute the traditional materials with carbon fiber composites in the secondary structures and later on in the primaries.

\section{TEST SPECIMENS}

The joint considered here is a double lap, with CRES hi loks (HL 18-6-8) in two rows (Fig. 1). The hi lok have protruding heads, and a notched collar, to apply a well defined tightening torque. In the collar there is a washer, in order to limit the damage on the surface of the laminate, and to increase the

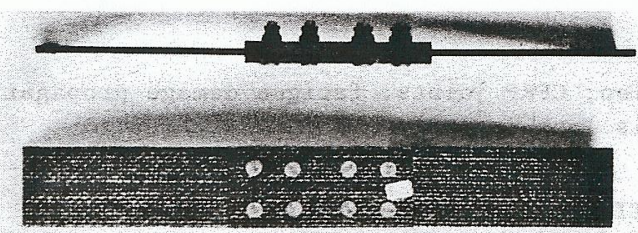

Fig. 1. The double lap joint tested

fatigue strength. The specimens were cut from a graphite-epoxy laminate, with the following stacking sequence

$$
\left((0,90) / 90 / 0_{2} / \pm 45 / 0 / \pm 45 / 0 /( \pm 45)\right)_{S} \text {. }
$$

The holes were drilled using a jig to control the tolerances, with the pieces in the assembly position. The pneumatic drill had a "house made" tool (D'Apuz zo, 1976). Before the assembly, the fabrication defects were controlled by ultrasonic inspection; the main design and production parameters, that may influence the fatigue strength, were evaluated. These parameters are: 1) hole diameters; 2) delaminations; 3) hole perpendicularity (measured randomly); 4) thickness and width of the joints; 5) hi lok diameters; 6) hi lok taper (measured randomly); 7) hi lok bearing; 8) clamping torque (measured randomly). For each hole, two perpendicular diameters were measured with a micrometer gauge. The delamination due to drilling (Fig. 2) were measured on the external rows with an optical microscope with a $0.05 \mathrm{~mm}$ resolution. The delasinestuth limits are: $0.10 \mathrm{~mm}$ minimum, 0.466 average, 2.3 maximum. The hole perpendlit limits are: larity deviation is me holes with a ver joints wer holes, the deviations from the nomina nier gauge. Also for hi loks a universal mea diameter were measured with electronic equipment connected this can be consisuring machine. The measured taper was unsatisfactory, dered to have a detrimental effect on the fatigue behaviour of the joint. The

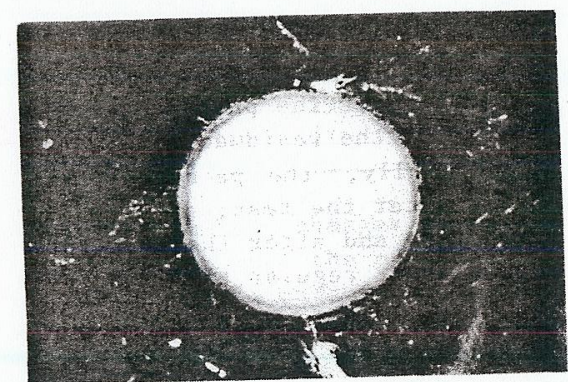

Fig. 2. The delamination due to the drilling

shank bearing, even low, may be important for the connection of the holes. shank bearing, even the The clamping torque supplier. All the data on the specimen range of $25 \div 35 \mathrm{in} \cdot \mathrm{lb}$, as declared by the supplier. geometry, even though very close to each other, were always diftic and fatithe specimens, and then a big scater may be expected in the static and fatigue tests. The detailed knowledge of this data can help very much in the evague the results, even though a correlation the measured parameters must be made statistically.

\section{DAMAGE PARAMETERS}

Before the start of the assembled specimen tests, the damage must be defined and the parameters for the damage measurement during the fatigue loads appli cation must be identified.

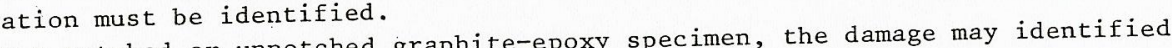
In a notched as the delamination that always grows during (De Iorio and Mignosi, 1983). fiber breakage endangers the static strength (De lorio and Mignosions from the In the joint, the mechanical damage occurs before the delaminations from the beginning of the test and there is a little slippage between the joint parts that increases with the number of cycles. If the load level is higher the slippage rate increases. When the slippage reaches the value of the minimum slippage rate increas holes, the hi lok involved works in shear, rather then clearance between the holes, fhe load side of the hole. It is the in tension, causing bearing failure load tran same for the other holes as load transfer occurs. In the joint, In the begin sfer is not the same at the beginning and at the end of the test. In the begin ning the hi lok works in tension, each one giving a contribution to the load 
transfer, proportional to the applied clamping torque; at the end the same hi loks work almost only in shear. The phenomenon is most critical if the initial clearance is greater. In the middle phase, the hi loks work in a mixed way: in tension and shear. It follows that the laminate damage is different going from a delamination (until the hi loks work in tension and if the loads are high enough, for a long time) to an excessive strain in the bearing area (when the hi loks work in shear). In these conditions, it is a problem to choose a dama ge parameter able to interpret the complex phenomenon, with sensitivity not only for the geometric and structural differences, but also for the damage due to the fatigue loads.

In a previous work, relative to simply notched specimens (De Iorio, Mignosi and Schiavone, 1983) we spoke about the opportunity of assuming the residual strain as a damage parameter. In the present case it seems better to consider other parameters, instead of the residual strain, which is difficult to inter pret for the joints. Initially, the parameter used was the "stiffness", mea sured before, during and after the test; after that the "damping" was ", mea also measured before, during and after the test; at the "nd the "load-strain cycle" was chosen outputted at regular time intervals during computer control led tests.

\section{TESTS AND RESULTS}

In order to run the tests, the specimens were assembled and the clearance bet ween the hole and the shank were measured. The minimum clearance in the exter nal rows and the average clearance in the first and in the last row were measu red, this because during tests the specimens always broke in an external row. In a group of specimens, the stiffness was evaluated before the fatigue test looking at the slope of first straight segment of the load-strain curve, recor ded by a universal test machine. The damping coefficient was also measured on the specimens subjected to forced flexural oscillations. The measured values for the specimens were plotted versus the cycle number, showing that the two parameters follow a different law. Therefore was decided to record during fatigue tests the hysteresis loop in order to evaluat both the elastic nodur the elastic modulus and the damping coefficient. The hysteresis loop area, A, proportional to the dissipated energy per cycle, $E_{d}$, is shown in Table 1 together with the total strain, $\varepsilon_{t}$, and the damping factor, $\eta$, defined as the ratio of the dissipated energy to the maximum elastic strain energy, $E_{e}$, times $2 \pi$, at some partial du rations, $\mathrm{n}$, for two specimens under fatigue load level $\mathrm{s}=1500 \mathrm{daN}$.

TABLE 1 Some Parameters of the Hysteresis Loop During the Fatigue Tests

\begin{tabular}{|c|c|c|c|c|c|c|}
\hline $\mathrm{n}$ (cycles) & $\mathrm{n} / \mathrm{N}(\%)$ & $\overline{\varepsilon_{\mathrm{t}}}$ & $\mathrm{A}\left[\mathrm{mm}^{2}\right]$ & $\mathrm{E}_{\mathrm{d}}[\mathrm{daN} / \mathrm{mm}]$ & $\mathrm{E}_{\mathrm{e}}$ & $\eta(\%)$ \\
\hline \multicolumn{7}{|c|}{ Specimen II-F-2 ; N (fatigue life) $=152090$ cycles } \\
\hline 4000 & 2.6 & .64 & 475 & 237 & 4.80 & 7.8 \\
\hline 8000 & 5.3 & .69 & 465 & 232 & 5.17 & 7.1 \\
\hline 12000 & 7.9 & .72 & 455 & 227 & 5.40 & 6.7 \\
\hline 16000 & 10.5 & .74 & 460 & 230 & 5.55 & 6.6 \\
\hline 20000 & 13.1 & .73 & 435 & 217 & 5.47 & 6.3 \\
\hline 24000 & 15.8 & .76 & 450 & 225 & 5.70 & 6.3 \\
\hline
\end{tabular}

continued

\begin{tabular}{|c|c|c|c|c|c|c|}
\hline n (cycles) & $\mathrm{n} / \mathrm{N}(\%)$ & $\varepsilon_{\mathrm{t}}$ & $\mathrm{A}\left[\mathrm{mm}^{2}\right]$ & $\mathrm{E}_{\mathrm{d}}[\mathrm{daN} / \mathrm{m}$ & $\mathrm{mm}] \mathrm{E}_{e}$ & $n(\%)$ \\
\hline \multicolumn{7}{|c|}{ Specimen $\mathrm{II}-\mathrm{H}-3$} \\
\hline 4200 & 2.6 & .108 & 700 & 371 & 9.72 & 6.1 \\
\hline 6000 & 3.7 & .111 & 680 & 360 & 9.99 & 5.7 \\
\hline 8000 & 5.0 & .114 & 665 & 352 & 10.26 & 5.5 \\
\hline 11000 & 6.8 & .122 & 635 & 336 & 10.98 & 4.9 \\
\hline 30000 & 18.6 & .123 & 610 & 305 & 11.07 & 4.4 \\
\hline 35000 & 21.7 & .125 & 620 & 310 & 11.25 & 4.4 \\
\hline 40000 & 24.8 & .127 & 580 & 290 & 11.43 & 4.0 \\
\hline 45000 & 28.0 & .124 & 550 & 275 & 11.16 & 3.9 \\
\hline
\end{tabular}

Furthermore, increasing the cycle number, changes the shape of the hysteresis loop (Fig. 3), due to the deterio ration of the mechanical coupling between the lap and overlap during the fatigue. This circumstance encouraged us to conti lap to investigate by means of the hysteresis loop in order to better under nue to in pos-. sible, with the geometric and load parameters.

At in running tests and to plot the hysteresis loop each 1000 cycles. The results

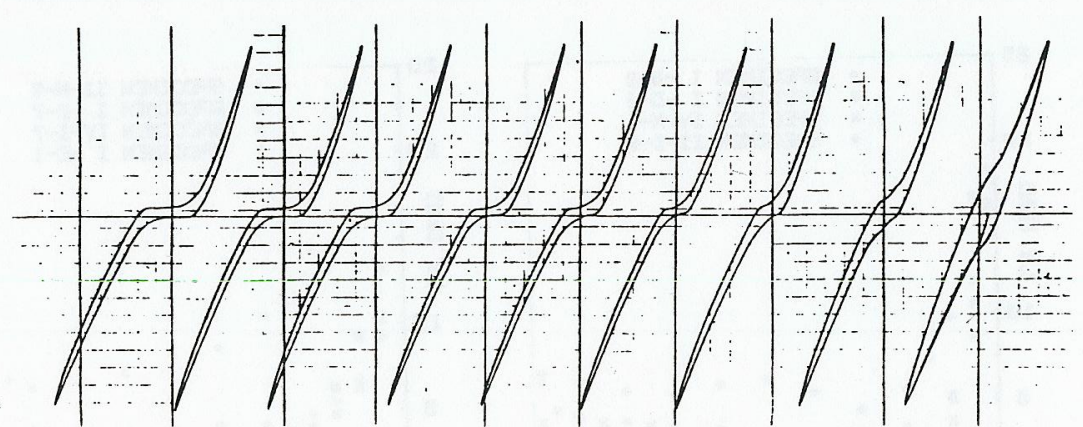

Fig. 3. The hysteresis loop changes during the fatigue

are in Figs $4 \div 6$; it can be seen that the total cycle area (the central are in figs cycle area is related the length of the central zone of the cycle due to the recovery of the clearances between holes and hi loks, change during the joint fatigue.

\section{CONCLUSIONS}

The damage mechanism of the CFRP joints is very complex, but it is possible to follow its evolution by measuring the global effects with one of the fol- 
lowing parameters: - The total stiffness and/or the damping of the joint eva luated with the hysteresis loop, recorded by a computer controlled test mach ne during the fatigue test; - That part of the area of hysteresis loop due to
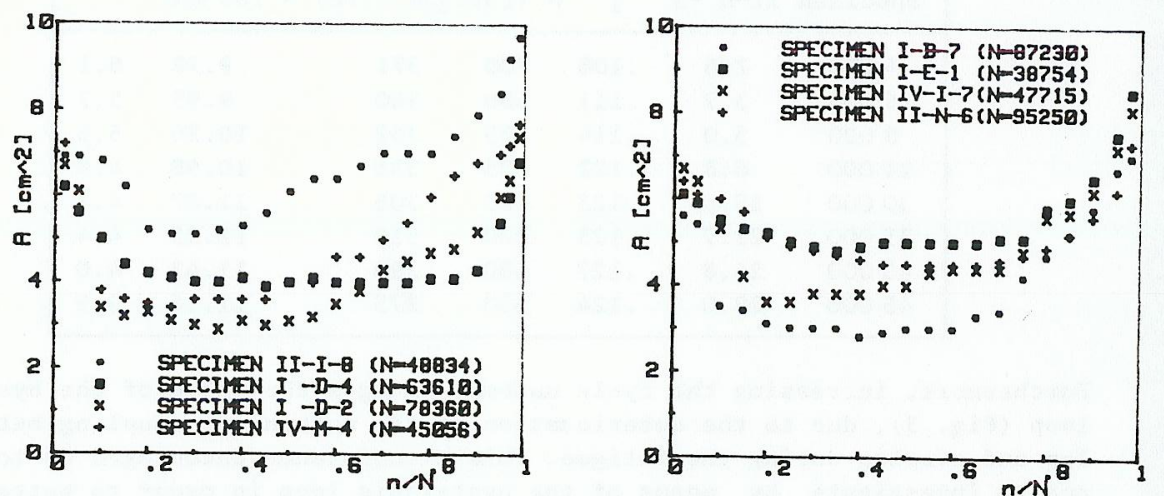

Fig. 4. The total cycle area variation during the fatigue.

the slippage, or the horizontal length of this loop. This length in fact in creases regularly from beginning of the test, up to the falure, as well as the fatigue damage. A correlation can be established between the fatigue damage
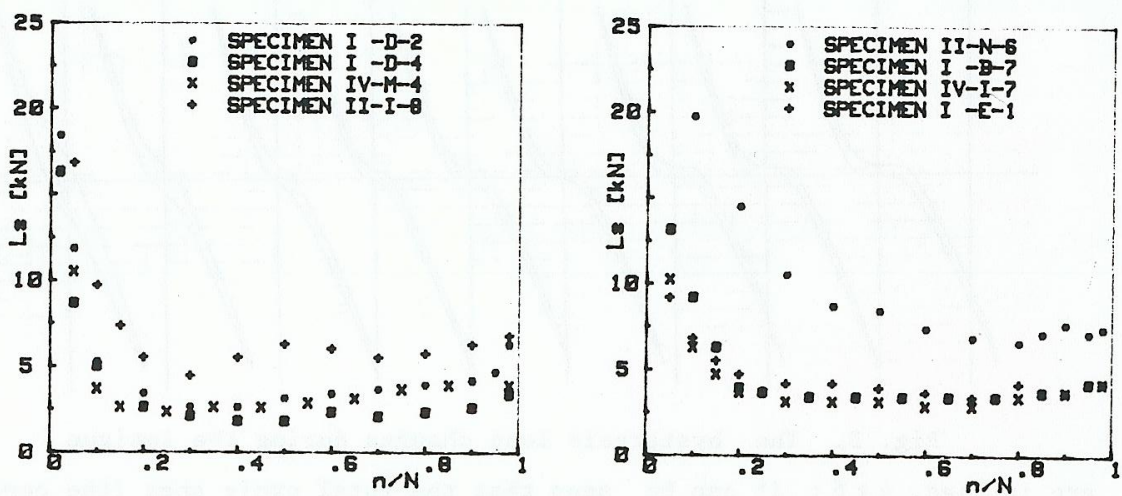

Fig. 5. The slippage load, $\mathrm{L}_{\mathrm{S}}$, variation during the fatigue.

and this length, normalized to the largest averaged clearances in the external rows. In this way the damage could be quantified just by means of the length parameter now defined. The length parameter measures the clearance recovery due to "the slippage force" decrease at beginning of the test, and to increase of the bearing.

The material delamination, that arise over of the $50 \%$ or $75 \%$ of the specimen life, has no easy correlation with the above defined parameters, but surely
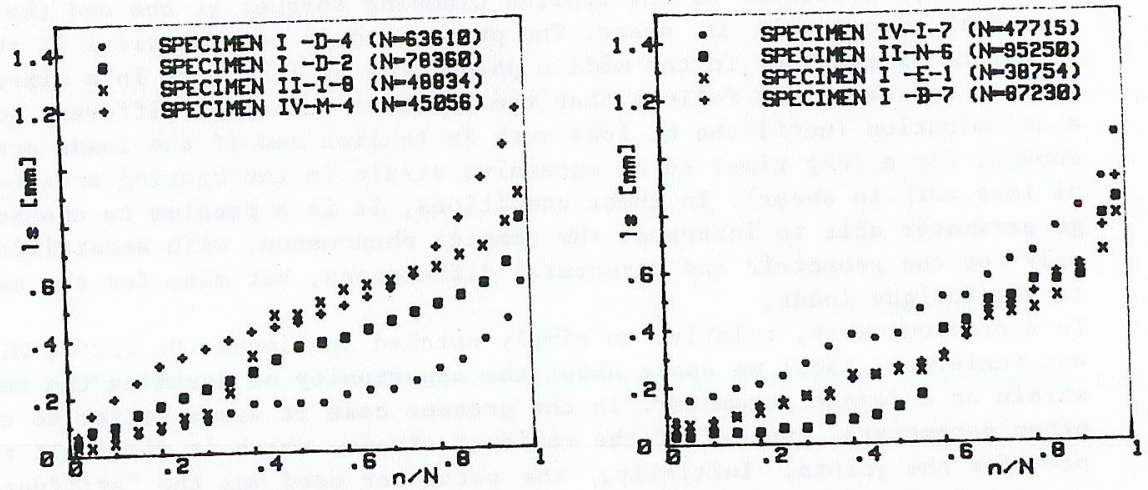

Fig. 6. The slippage length, $1_{s}$, variation during the fatigue.

influences their behaviour and value.

\section{REFERENCES}

(1979). Static Agarwal, L. L. (1979). Statictures, Structural Dynamics and Materials Conf., St. Luis, Mo.

Stima Ioading. Proc. ICCM-IV, Tokyo.

esting (1980). Fatigue in (atigue in Aerospace Structures, A.I.F.A., Naples.

Ai-Hung Shen, and G. S. Springer (1977). Effects of moisture and temperature on the tensile strength of composite materials. J. Composite Materials, Vo1. II, n.1.

'Apuzo, S. (1976). Foratura della carboresina. AIT Report, Aeritalia S.a.i.p.a. Pomigliano d'Arco, Italy.

De 2nd Intern. Meeting on Composite Materials, Milano.

83). Fatigue in CFRP under varia ble amplitude loading. TEQC83, Guildford, England.

Garbo, S. P., and J. M. Ogonowski (1979). Strength prediction of composite la minates minates and Materials Conf., St. Louis, Mo.

Dynamics, and haterials Conf. Hart Smith, L. J. (1980). Mechanically fastened jois. In Lenoe, Oplinger. Phenomenological considerations and simple analy Design, Plenum Press, New York. Burke (Ed.), Fibrous Composites in composite materials. AGARD R638. Reifsnider, K. L. (1976). Fatigue in composite materiath of plain, notched and $\mathrm{jointed}$ specimens of carbon fibres composites. LBF Report.

and ched strength of laminated composites. ASTM STP 717. 